\title{
Dithioacetals as geminal dication synthons
}

\author{
Tien-Yau Luh \\ Department of Chemistry, National Taiwan University, Taipei, Taiwan 106
}

\begin{abstract}
The $\mathrm{NiCl}_{2}\left(\mathrm{PPh}_{3}\right)_{2}$-catalyzed cross coupling reactions of benzylic and allylic dithioacetals with alkyl Grignard reagents give the corresponding olefination products. The reactions of the dithioacetal with cyclopropyl Grignard reagent under the same conditions provide a stereoselective synthesis of substituted butadienes. The applications of this methodology lead to a unified synthesis of vinylsilanes and silyl-substituted butadienes. The aliphatic dithioacetals can undergo the coupling reaction when there exists a proximal heteroatom which, in combination with the sulfur moeity, can form a chelation complex with the nickel catalyst. Trithioorthoesters and tetrathioorthocarbonate behave similarly to yield the corresponding alkylative olefination products. The nickel catalyst having a bidentate phosphine ligand can promote geminal dimethylation of allylic dithioacetals under similar conditions. These reactions can be considered as using dithioacetals as $\mathrm{C}^{2+}$ synthons.
\end{abstract}

\section{INTRODUCTION}

The most common approach in retrosynthesis is to disconnect a carbon-carbon bond into an electrophile and a nucleophile. ${ }^{1}$ The carbon electrophile can thus be described as a $\mathrm{R}_{3} \mathrm{C}^{+}$.synthon. By analogy, the $\mathrm{R}_{4-n} \mathrm{CX}_{n}$ species, where $n$ equals to 2 to 4 , can be viewed as $\mathrm{R}_{4-n} \mathrm{C}^{n+}$ synthons. However, it is known that gem-dihalides are less reactive toward nucleophilic substitution than the corresponding monohalides. ${ }^{2}$ When the $\mathrm{C}-\mathrm{X}$ bonds are progressively substituted, the steric environment at the electrophilic carbon becomes more crowded and the reactivity becomes lower. ${ }^{3}$ In addition, upon treatment with an organometallic reagent RM, metal-halogen exchange reaction may occur, leading to an $\alpha$-halo-substituted organometallic species which may undergo $\alpha$-elimination to produce a carbenoid intermediate (eq 1). ${ }^{4}$

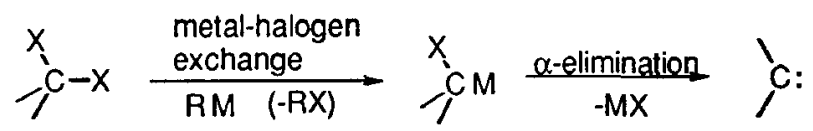

In spite of the above limitation, the applications of $\mathrm{R}_{4-n} \mathrm{CX}_{\mathrm{n}}$ as a polyelectrophilic center for multiple carbon-carbon bond formation have become increasingly useful in organic synthesis. 5 An intriguing approach uses a relatively poor leaving group such that either the $\mathrm{M}-\mathrm{X}$ exchange (step 1 ) or the $\alpha$-elimination process shown (step 2) in eq 1 can be avoided. The involvement of organosulfur compounds to convert the carbon-sulfur bond(s) into carbon-carbon bond(s) has been exceedingly useful.6,7 Transition metal catalysts or reagents have demonstrated a pivotal role for such synthetic endeavor. This review summarizes the recent development on the use of dithioacetals and related compounds as a polyelectrophilic center in organic synthesis. The most frequent practice of this functionality is confined to serve as a latent carbonyl or methylene group. ${ }^{8}$ Substitution of the two carbon-sulfur bonds in dithioacetals by carbon-carbon bonds in one pot can be versatile in synthesis. With the aid of a nickel catalyst, two interesting transformations involving the dithioacetal functionality have been recorded. In the first instance, one of the carbon-sulfur bonds is substituted by a carbon-carbon bond, and subsequently the second carbon-sulfur bond is eliminated to produce an olefin. The second type of the transformation involves the replacement of both carbon-sulfur bonds by carbon-carbon bonds which results in geminal dialkylation.

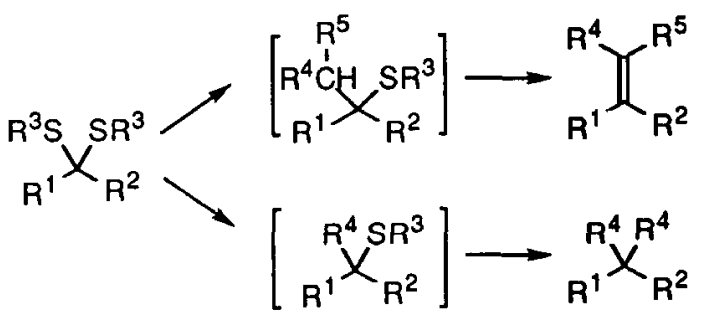




\section{NICKEL-CATALYZED OLEFINATION REACTIONS OF BENZYLIC AND ALLYLIC DITHIOACETALS}

\section{Prototype}

Under the nickel catalyzed conditions, benzylic dithioacetals react with straight chain alkyl Grignard reagents to afford the corresponding styrenes. ${ }^{9}$ Dithioacetals of cyclic ketones give exclusively endocyclic olefins; even the highly sterically hindered dithioacetal produces the corresponding exocyclic olefin in $78 \%$ yield. ${ }^{9}$ The reaction forms the prototype of using dithioacetals as dication synthons. Functional groups such as $\mathrm{F}, \mathrm{Me}_{3} \mathrm{Si}, \mathrm{Me}_{3} \mathrm{Sn}$ and alkoxy group remain intact under the reaction conditions.

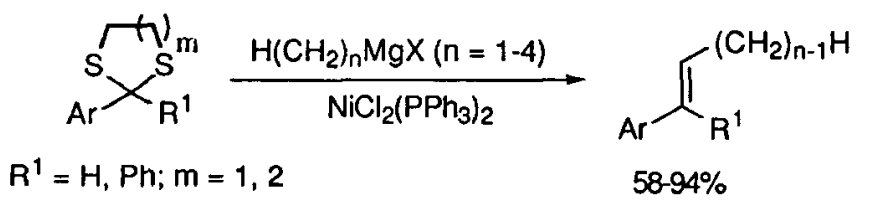

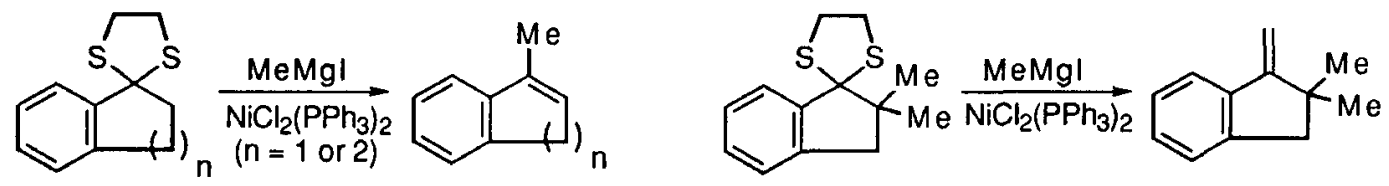

Since palladium is an active catalyst for the cross coupling of Grignard reagents with aryl halides (Kumada-Corriu reaction) but not with dithioacetals, selective transformations have been achieved. 9

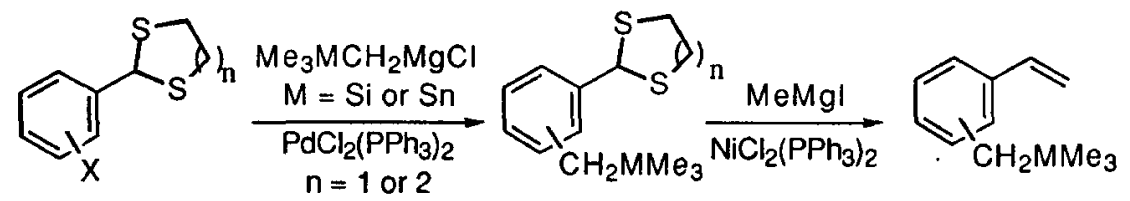

\section{Mechanism}

The mechanism for the nickel-catalyzed olefination of the benzylic dithioacetal with the Grignard reagent is outlined in Scheme 1.9 Several interesting features about this catalytic cycle are worthy of comment. First, the formation of the carbon-carbon bond precedes the elimination step. Second, the intermolecular nickel-catalyzed reaction of the first carbon-sulfur bond of the dithioacetal moiety will promote the further reaction of the second carbon-sulfur bond because of the involvement of the chelation in intermediate 1.11 The high reactivity found in benzylic dithioacetals versus low activity observed for benzylic thiols or thioethers under the nickel catalyzed cross coupling reactions ${ }^{7}$ indicates that the overall reaction is a cascade process. Third, both sulfur atoms derived from the dithioacetal moiety may coordinate to the nickel throughout the catalytic cycle. ${ }^{12}$ It seems likely that one of the phosphine ligands in $\mathrm{NiCl}_{2}\left(\mathrm{PPh}_{3}\right)_{2}$ catalyst may dissociate during the course of the catalytic cycle to generate a 16-electron species which undergoes $\beta$-hydride elimination to give the corresponding olefins. It is interesting to note that the yield of olefination products becomes poorer when the nickel catalyst contains a bidentate ligands. The fourth point concerning the catalytic cycle is the requirement of the second equivalent of the Grignard reagent for the elimination step.

Although $\beta$-hydride elimination of the organometallic intermediate 2 is a facile step for the double bond formation, the alkoxy or thioalkoxy group at the $\beta$-position can also be eliminated easily leading to the olefination product. ${ }^{13}$

\section{Applications}

The reactions of the benzylic dithioacetals with a cyclopropyl Grignard reagent furnish a useful stereoselective synthesis of substituted butadienes. Hexatrienes are obtained from the reaction of the corresponding allylic dithioacetals. ${ }^{14}$

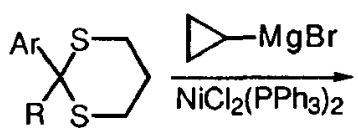

$R=H$, alkyl or aryl
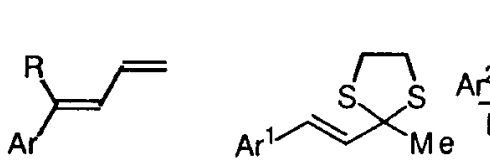


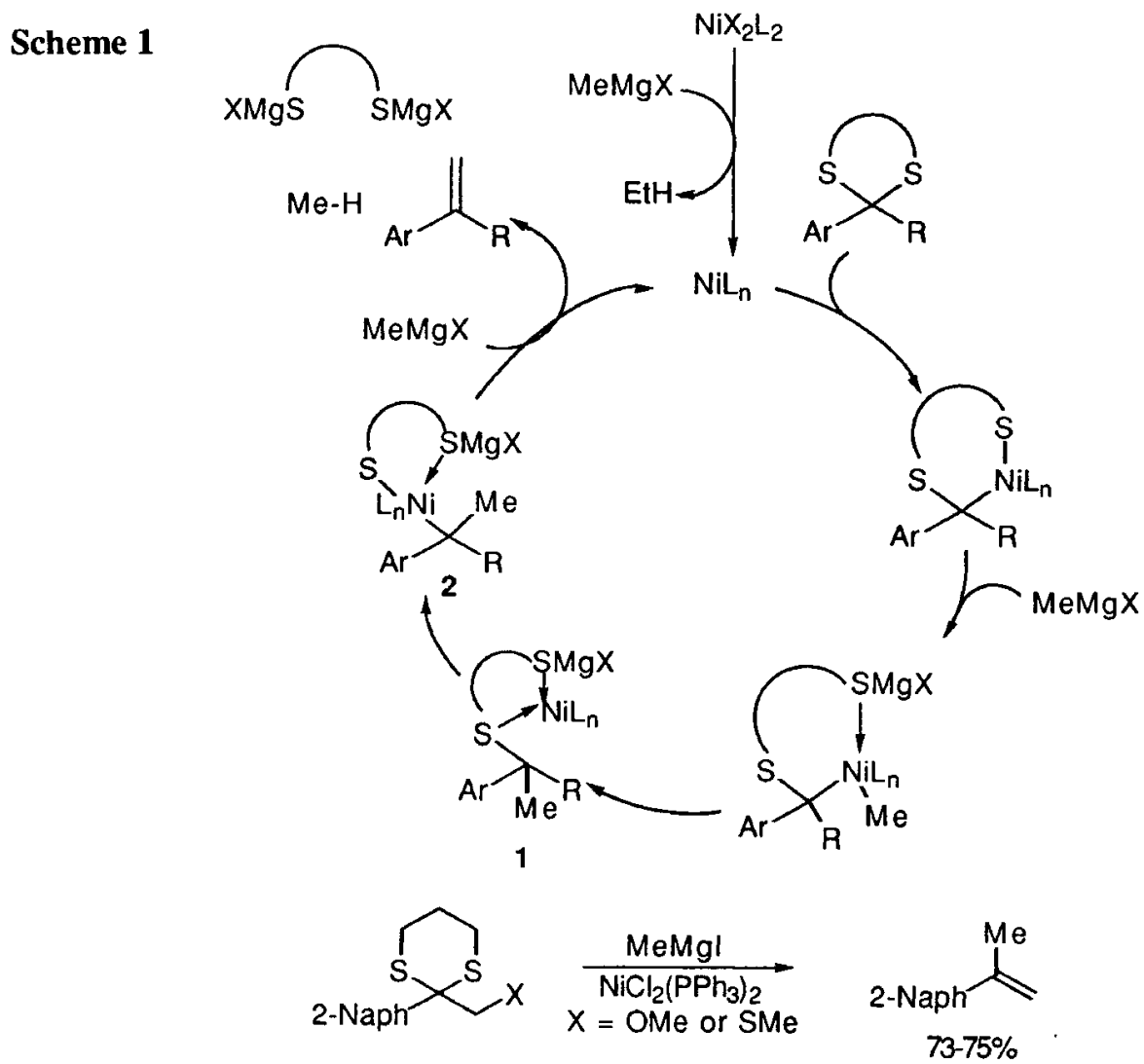

According to the mechanism shown in Scheme 1, the reaction may involve a cyclopropylcarbinyl nickel intermediate 3 . The ring opening of 3 yields a homoallyllic metal species 4 which may then undergo $\beta$-hydride elimination giving a butadiene complex 5 . Re-addition of the metal hydride to the coordinated diene may occur to give the thermodynamically more stable $\pi$-allyl complexes $6 .{ }^{15}$ Since the $\beta$-hydride

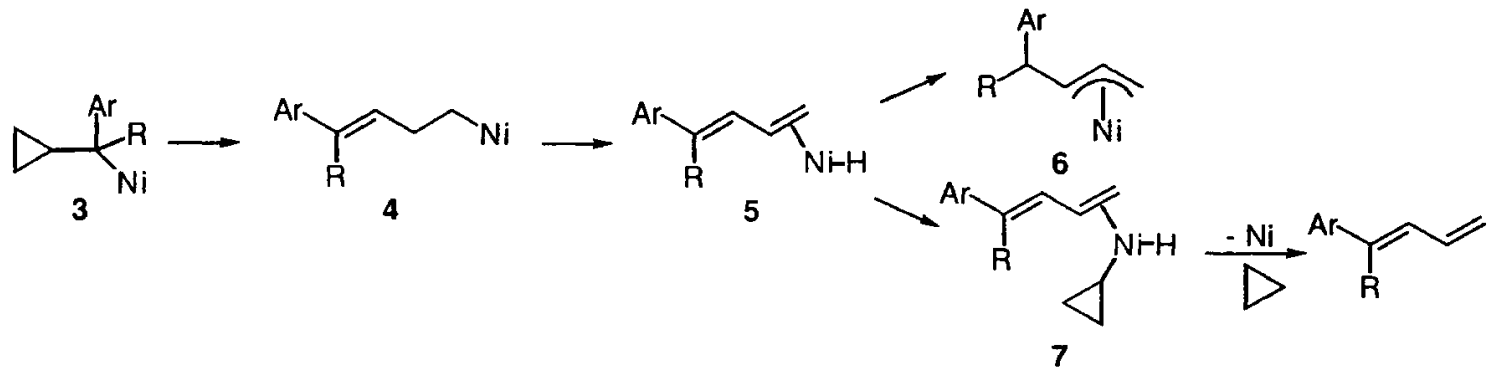

elimination in the nickel-catalyzed cross coupling reactions of benzylic dithioacetals requires the association of the Grignard reagent (Scheme 1), intermediate 7 may rapidly undergo reductive elimination liberating cyclopropane and butadiene.

The product distribution of the reaction of dithioacetals with 2-substituted cyclopropyl Grignard reagents depends on the nature of the substituent. When $\mathrm{R}^{2}$ is an aryl group, regioselective rearrangement occurs and terminal aryl-substituted butadienes are formed exclusively. However, a mixture of substituted butadienes is obtained when $R^{2}$ is an alkyl group. ${ }^{14}$

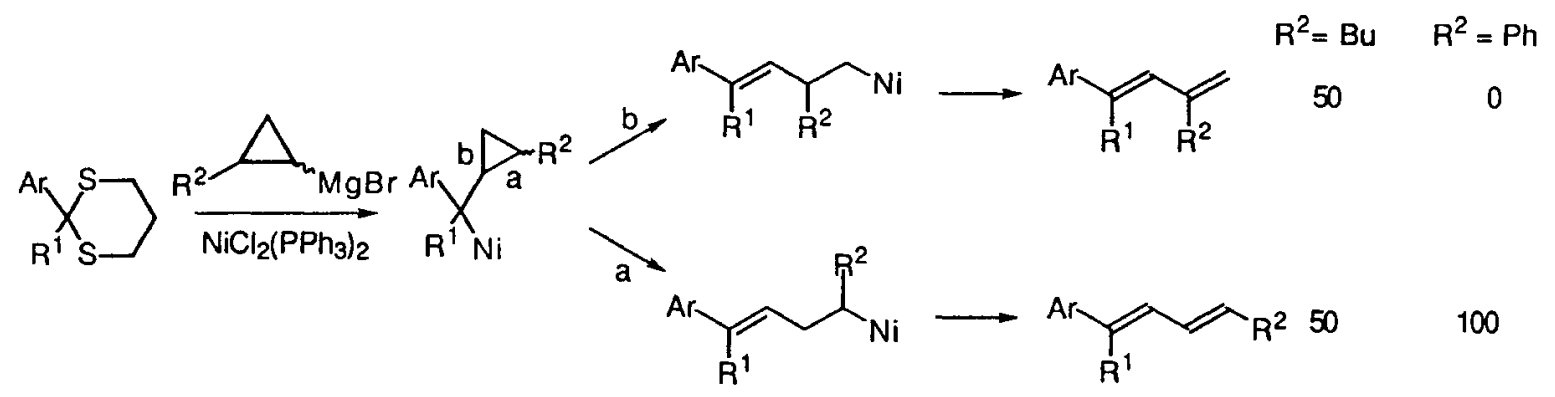


In contrast to the simple aliphatic substituents, treatment of 2-alkoxy- or thioalkoxymethylcyclopropyl Grignard reagents with dithioacetal yields the corresponding 1,4-dienes. When 2-butoxycyclopropylmagnesium bromide is employed, the corresponding butadiene is obtained. 14<smiles>C=CCC=C(c1ccccc1)c1ccccc1</smiles>

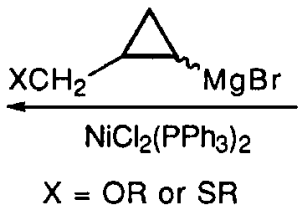<smiles>[H][R]([H])(c1ccccc1)C1(P)SCCS1</smiles>

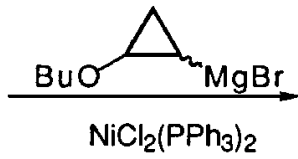<smiles>C=CC=C(c1ccccc1)c1ccccc1</smiles>

The coupling reactions involving cyclopropyl Grignard reagents illustrate the first example using a cyclopropyl anion as an allyl anion synthon. It is noteworthy that the reactions of benzylic dithioacetals derived from alkyl aryl ketones with allylmagnesium halides under these conditions afford 1,4-pentadiene derivatives as the predominant, if not exclusive, products. $9 \mathrm{~b}$

The nickel-catalyzed coupling reactions have provided a particularly useful procedure for the stereoselective synthesis of different kinds of vinylsilanes and silyl-substituted butadienes. By employing the cyclopropyl Grignard reagent, 1-aryl-1-trimethylsilylbutadienes can be synthesized stereoselectively. Bisvinylsilanes are synthesized similarly from the corresponding bisdithioacetals. Halo-substituted-aryl dithioacetals afford the one-step synthesis of the compound having both a vinylic and a benzylic silyl group. 16
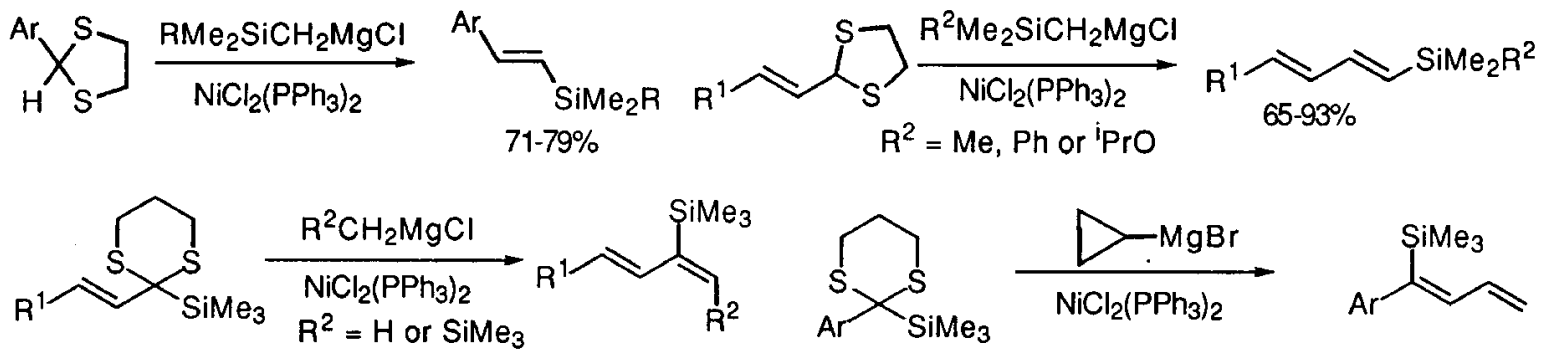<smiles>CCC1([AlH2])SCCCS1</smiles><smiles>CC1CC1[R16](Br)c1ccccc1</smiles><smiles>C=C/C=C(\[Mg])[Ga]</smiles>

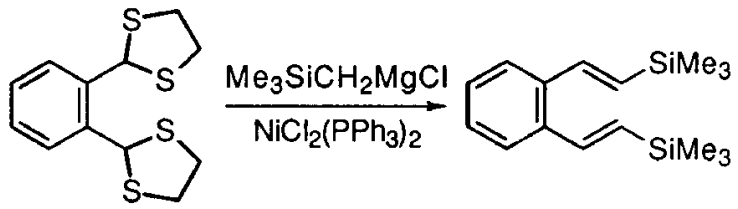<smiles>Brc1ccccc1C1SCCS1</smiles>

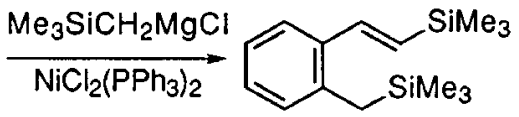

In contrast to silyl-substituted Grignard reagents, the reactions of benzylic dithioacetals with $\mathrm{Me}_{3} \mathrm{SnCH}_{2} \mathrm{MgI}$ in the presence of a catalytic amount of $\mathrm{NiCl}_{2}\left(\mathrm{PPh}_{3}\right)_{2}$ produce styrenes in good yield. 17 No transmetallation of vinylstannanes under the reaction conditions has been established. $\beta$-Elimination of $\mathrm{Me}_{3} \mathrm{Sn}$ group in the corresponding organonickel intermediate gives styrenes preferentially.
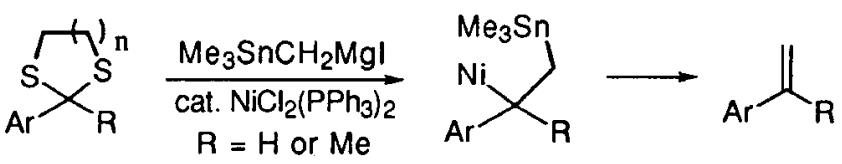

\section{CHELATION-ASSISTED CROSS COUPLING REACTIONS OF ALIPHATIC DITHIOACETALS}

The cross coupling reactions mentioned above are either benzylic or allylic dithioacetals. As expected, simple aliphatic substrates do not react under these conditions. In fact, only limited cases for the alkyl iodides are known to undergo coupling reactions with aryl Grignard reagents in the presence of a nickel catalyst or with borane reagents under Suzuki reaction conditions. 18 Side reactions such as reduction or dimerization via a radical intermediate or $\beta$-hydride elimination would readily occur. ${ }^{18 \mathrm{c}}$ Several interesting approaches have recently been developed for the activation of the specially designed aliphatic dithioacetal functionality under the nickel-catalyzed cross coupling conditions.

As mentioned earlier (cf Scheme 1), chelation plays a unique role in the enhancement of the reactivity of the $\mathrm{C}-\mathrm{S}$ bond in benzylic dithioacetals. It is known that the $\mathrm{C}-\mathrm{S}$ bonds in certain complexes containing thiolato ligands are activated. ${ }^{19}$ Accordingly, a specially designed substrate which can form such a complex will increase the reactivity of the C-S bond in the oxidative addition reaction. The strategy is 
outlined below. When a dithioacetal moiety, having other heteroatom(s) $\mathrm{Y}$ at a proximal position, is treated with the Grignard reagent in the presence of a nickel catalyst, a chelation complex would be expected. Nickel-catalyzed olefination of the dithioacetal moiety with the Grignard reagent might then occur. 20<smiles>[R]/C=C\CC[Y]</smiles>

Based on this conjecture, treatments of bisdithioacetals with excess $\mathrm{MeMgI}$ in the presence of $5 \mathrm{~mol} \%$ of $\mathrm{NiCl}_{2}\left(\mathrm{PPh}_{3}\right)_{2}$ afford olefin-dithioacetals in good yield. When bisdithioacetals derived from 1,3-diketones are employed, homoallylic dithioacetals are obtained regioselectively. Presumably, the nickel moiety of intermediate may form a chelation complex with the sulfur atom in the remaining dithioacetal moiety. Since the exocyclic $\mathrm{C}-\mathrm{H}$ bond in $\mathbf{8}$ can readily exist the preferred cis-coplanar conformation relative to the carbon-nickel bond, $\beta$-hydride elimination would lead preferentially to the formation of the corresponding homoallylic dithioacetals. The general criterion for the success of these transformations depends on the ability of the two sulfur moieties coordinating simultaneously to the nickel-catalyst. Poor chelation results in the recovery of a significant amount of the starting materials. For example, the reaction of 9 with $\mathrm{MeMgI}$ under these conditions leads to the $91 \%$ recovery of the starting material.
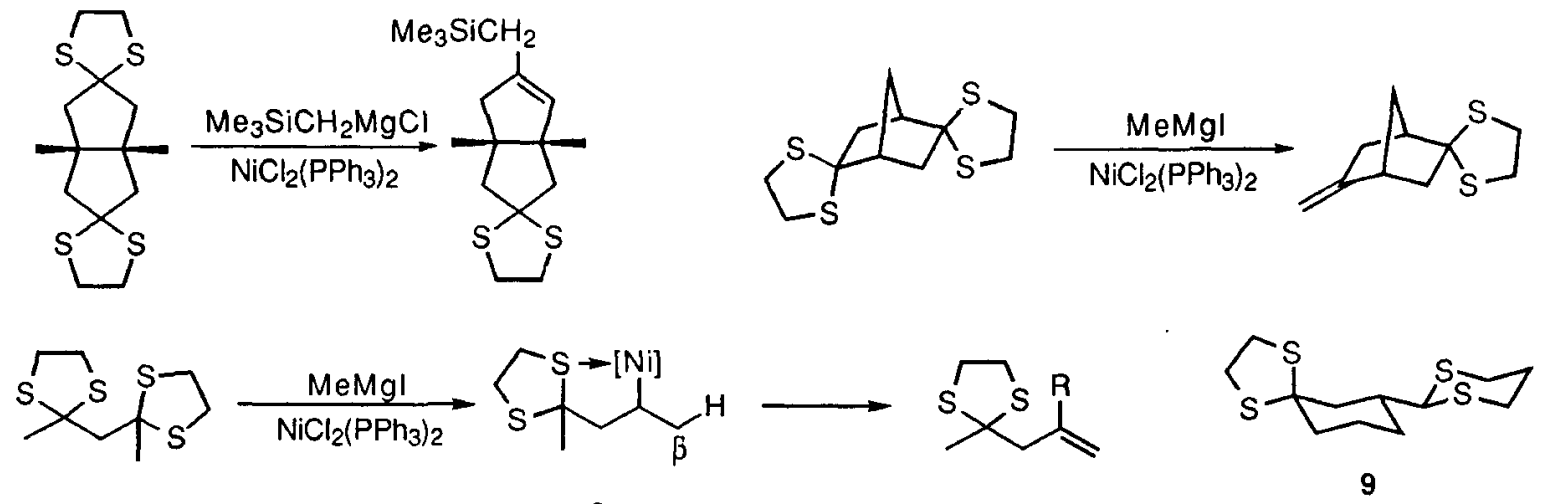

8

It is noteworthy that only one of the dithioacetal groups of these substrates undergoes olefination reaction, even in the presence of a large excess of the Grignard reagent. This reaction can thus be considered as a selective modification of one of the two carbonyl equivalents, while the remaining one is still protected.

Heteroatom substituents such as hydroxy, methoxy, amino or thioalkoxy groups also assist the olefination of aliphatic dithioacetals; and homoallylic derivatives are obtained regioselectively in fairly good yields. It is noteworthy that the thioether linkage is also cleaved under these conditions.

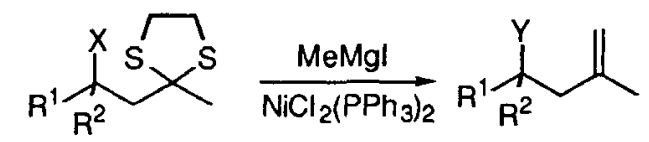

$R^{1}, R^{2}=$ alkyl or $H ; X=S H, S E t, H S\left(C_{2}\right)_{2} S ; Y=S H$

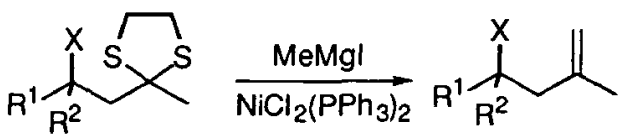

$\mathrm{R}^{1}, \mathrm{R}^{2}=$ alkyl or $\mathrm{H} ; \mathrm{X}=\mathrm{OH}, \mathrm{OMe}, \mathrm{NMe}_{2}$

The use of the heteroatom-assisted olefination of dithioacetals has been extended to a sugar derivative 10. In the presence of the nickel catalyst, the oxygen-atom assisted olefination of the dithioacetal group coupled with the regioselective ring opening of both acetonide moieties occurs to give 11 . When the nickel catalyst is absent, 12 is obtained and the carbon-sulfur bonds remain intact. $20 \mathrm{~b}, 21$<smiles>C=CCC(OCC)C(O)C(O)COCCCC</smiles>

11<smiles>CC[Si]CC1OC(C)(C)O[C@H]1C1COC(C)(C)O1</smiles>

10

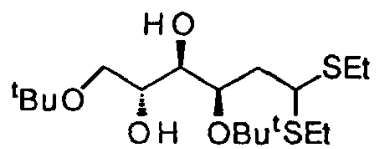

12 


\section{REACTIONS OF DITHIOACETALS WITH GEMINAL BISMETALLIC SPECIES}

The previous examples clearly demonstrate that the dithioacetal functionality can serve as a dication synthon for the carbon-carbon bond formation. Since geminal bismetallic species have been used as geminal dicarbanion equivalents, ${ }^{22}$ the couplings of these reagents with dithioacetals in the presence of a nickel catalyst give the corresponding olefins in good yield. 23

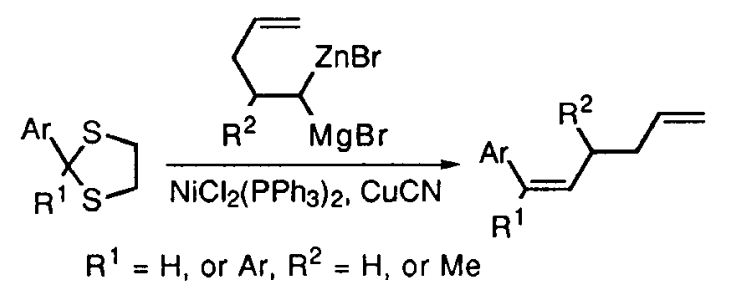

\section{BENZYLIC DITHIOACETAL-S-OXIDES OR TRITHIOORTHOESTERS AS RC ${ }^{3+}$ SYNTHONS}

It is known that sulfoxides which bear an $\alpha$-hydrogen atom undergo, upon treatment with Grignard reagents, a fascinating Pummerer-type rearrangement to form an $\alpha$-alkylated thioether. Under the nickelcatalyzed cross coupling reaction conditions, benzylic dithioacetal-S-oxides will give the corresponding benzylic dithioketals which undergo further cross coupling with the Grignard reagent to give an isopropenylated arenes. The overall process can thus be considered as using benzylic dithioacetal-S-oxide as an $\mathrm{ArC}^{3+}$ synthon. ${ }^{24}$ In a similar manner, the trithioorthoesters can serve as the corresponding $\mathrm{ArC}^{3+}$ synthons. 25

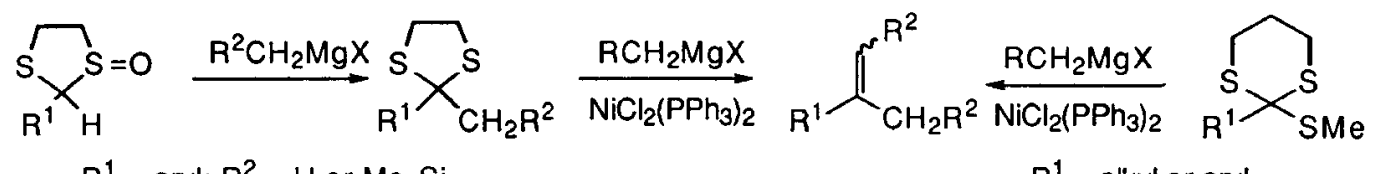

$$
\mathrm{R}^{1}=\operatorname{aryl} ; \mathrm{R}^{2}=\mathrm{H} \text { or } \mathrm{Me}_{3} \mathrm{Si}
$$$$
\mathrm{R}^{1}=\text { alkyl or aryl }
$$

\section{TETRATHIOORTHOCARBONATE AS A C4+ SYNTHON}

Whereas aliphatic orthothioesters readily undergo alkylative olefination reaction, an obvious extension to tetrathioorthocarbonate has been executed. Thus, sterically hindered alkenes as well as tris-silylsubstituted isobutenes are obtained conveniently. $25 \mathrm{~b}, 26$

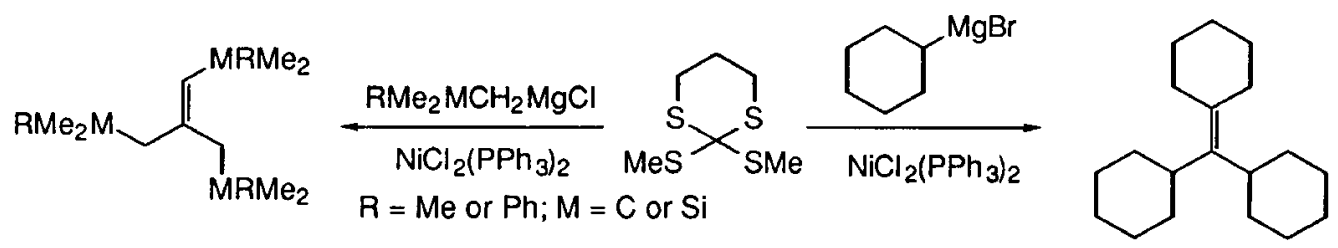

\section{GEMINAL DIMETHYLATION OF DITHIOACETALS}

As mentioned earlier, a 16-electron organonickel intermediate which undergoes facile $\beta$-hydride elimination forms the basis for the nickel-catalyzed olefination. When a bidentate ligand such as dppe $\left(\mathrm{Ph}_{2} \mathrm{PCH}_{2} \mathrm{CH}_{2} \mathrm{Ph}_{2}\right)$ or dppp $\left(\mathrm{Ph}_{2} \mathrm{PCH}_{2} \mathrm{CH}_{2} \mathrm{CH}_{2} \mathrm{PPh}_{2}\right)$ replaces the $\mathrm{Ph}_{3} \mathrm{P}$ ligand in the nickel catalyst, the phosphine ligand can no longer dissociate. The involvement of an 18-electron intermediate is likely to enhance the reductive elimination process resulting in the facile formation of the second carbon-carbon bond. Accordingly, the $\mathrm{NiCl}_{2}$ (dppe)-catalyzed reactions of allylic dithioacetals with $\mathrm{MeMgI}$ provides a unique procedure for the conversion of an $\alpha, \beta$-unsaturated carbonyl equivalent into the corresponding geminal dimethyl group regioselectively. Olefins having a t-alkyl substituent can be conveniently prepared. 27

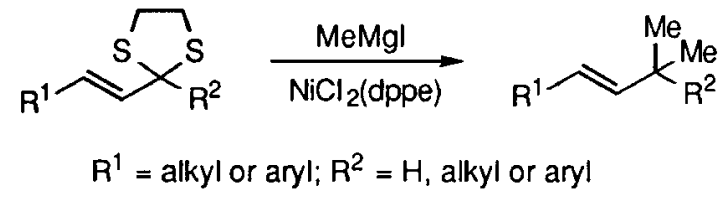

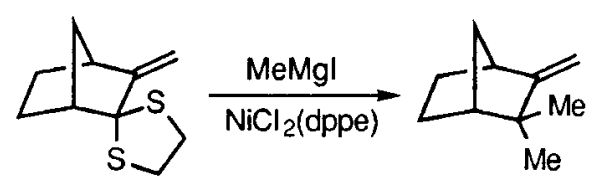


Interestingly, treatment of allylic trithioorthoesters with MeMgI under similar conditions yields the corresponding trimethylated products. $27 \mathrm{~b}$ The isolation of 13 indicates that the first methyl group is introduced at C-3. This reaction compliments with the geminal dimethylation of allylic dithioketals.

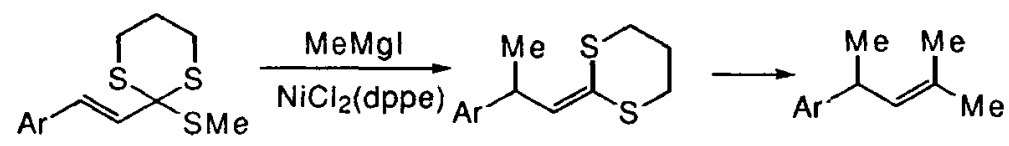

13

The extension of the geminal dimethylation to benzylic dithioacetals is not successful, only styrenes are obtained. ${ }^{9}$ Interestingly, the presence of an ortho amino group causes a dramatic change, e.g. 2 -isopropylaniline is obtainable in $60-70 \%$ yields. Apparently, this neighboring amino moiety may enhance the rate of reductive elimination leading to geminal dimethylation. An ortho hydroxyl group in the phenolic analogs, however, exhibits only a very weak effect; the corresponding styrenes were isolated as the predominant products. 27 Surprisingly, dithioacetals derived from aromatic aldehydes react with EtMgBr in the presence of $\mathrm{NiCl}_{2}$ (dppe) to yield the corresponding geminal diethyl products.<smiles>CC(C)c1ccccc1N</smiles>

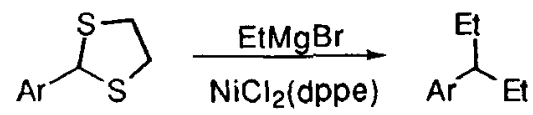

\section{CONCLUSION}

The chemistry described herein demonstrates some interesting applications of using dithioacetals, trithioorthoesters and tetrathioorthocarbonate as $\mathrm{R}_{4-n} \mathrm{C}^{\mathrm{n}+}$ synthons for multiple carbon-carbon bond formation. Certain unique transformations have been achieved by employing these substrates, the fascinating syntheses of vinylsilanes and silyl-substituted dienes from the corresponding dithioacetals being distinct examples. Olefination of acetals and dithioacetals serves as alternatives for the Wittig reactions of a carbonyl equivalent; and the geminal dimethylation of allylic dithioacetals adds another powerful arsenal in synthetic endeavor. These reactions represent an unequivocal demonstration of using $\mathrm{R}_{4-\mathrm{n}} \mathrm{CX}_{\mathrm{n}}$ as $\mathrm{R}_{4-\mathrm{n}} \mathrm{C}^{\mathrm{n}}$ synthons. Since the chemistry involving organosulfur compounds covers a wide area in organic synthesis, such a prospect provides a major impetus for continuing investigation of novel multiple carbon-carbon bond formation methodologies starting from $\mathrm{R}_{4-\mathrm{n}} \mathrm{CX}_{\mathrm{n}}$.

Acknowledgments. Thank are due to all collaborators, whose names are mentioned in the references, for their invaluable contributions which made all of this possible. This work has been supported by the National Science Council of the Republic of China.

\section{REFERENCES}

1. E.J. Corey and X.-M. Cheng, The Logic of Chemical Synthesis, Wiley, New York, 1989.

2. P.B.D.de la Mare and B.E. Swedlund, The Chemistry of The Carbon-Halogen Bond, S. Patai, Ed.,Wiley, Chichester, 1973, p. 407,

3. H.M. Bell, C.W. Vanderslice and A. Spehar, J. Org. Chem. 34, 3923 (1969).

4. W.T. Miller, Jr. and C.S.Y. Kim, J. Am. Chem. Soc. 81, 5009 (1959).

5. For a recent review, see: T.-Y. Luh and M.-K. Leung, In Advances on the Use of Synthons in Organic Chemistry, A.Dondoni, Ed., JAI, London, Vol 2, 1995, 000.

6. For reviews see: (a) T.-Y. Luh and Z.-J. Ni, Synthesis, 89, (1990). (b) T.-Y. Luh, Acc. Chem. Res. 24, 257 (1991). (c) F. Naso, Pure Appl. Chem. 60, 79 (1988). (d) V. Fiandanese, Pure Appl. Chem. 62, 1987 (1990).

7. (a) H. Okamura, M. Miura, and H. Takei, Tetrahedron Lett. 19, 43 (1979). (b) E. Wenkert, T.W. Ferreira and E.L. Michelotti, J. Chem. Soc., Chem. Commun. 637 (1979).

8. (a) T.A. Greene and P.G.M. Wuts, Protective Groups in Organic Synthesis, Wiley, New York, 2nd Ed. 1991. (b) F.A. Carey and R.J. Sundberg, Advanced Organic Chemistry, Plenum, New York, 3rd. Ed., 1990, Part B, p 266.

9. (a) Z.-J. Ni and T.-Y. Luh, J. Chem. Soc., Chem. Commun. 1515 (1987). (b) Z.-J. Ni, N.-W. Mei, X. Shi, M.C. Wang, Y.-L. Tzeng and T.-Y. Luh, J. Org. Chem. 56, 4035 (1991).

10. M. Kumada, Pure App. Chem. 52, 669 (1980).

11. M.C. Wang and T.-Y. Luh, J. Org. Chem. 57, 2178 (1992).

12. K. -T. Wong, Z.-J. Ni and T.-Y. Luh, J. Chem. Soc., Perkin Trans. 13113 (1991). 
13. L.-L. Shiu, C.C. Yu, K.-T. Wong, B.-L. Chen, W.-L. Cheng, T.-M. Yuan and T.-Y. Luh, Oragnometallics 12, 1018 (1993).

14. (a) D. K. P. Ng and T.-Y. Luh, J. Am. Chem. Soc. 111, 9119 (1989). (b) C.C. Yu, D.K.P. Ng, B.-L. Chen and T.-Y. Luh, Organometallics 13, 1487 (1994).

15. (a) H. Lehmkuhl, C. Naydowski, F. Danowski, M. Bellenbaum, R. Benn, A. Rufinska, G. Schroth and R. Mynott, Chem. Ber. 117, 3231 (1984) and references therein. (b) R.C. Larock and S. Varaprath, $J$. Org. Chem. 49, 3432 (1984) and references therein.

16. (a) Z.-J. Ni and T.-Y. Luh, J. Org. Chem. 53, 2129, 5582 ( (1988). (b)Z.-J. Ni, P.-F. Yang, D.K.P. Ng, Y.-L. Tzeng and T.-Y. Luh, J. Am. Chem. Soc. 112, 9356 (1990). (c) Z. -J. Ni and T.-Y. Luh, Org. Syn. 70, 240 (1991). (c) R.-M. Chen, W.-W. Weng and T.-Y. Luh, J.Org. Chem. 60, 3272 (1995).

17. X. Shi and T.-Y. Luh, Organometallics, 9, 3019 (1990).

18. (a) K. Yuan and W.J. Scott, Tetrahedron Lett. 32, 189 (1991). (b) T. Ishiyama, N. Miyaura and A. Suzuki, Tetrahedron Lett. 32, 6923 (1991). (c) K. Yuan and W.J. Scott, Tetrahedron Lett. 30, 4779 (1989).

19. N.-F. Ho, T.C.W. Mak and T.-Y. Luh, J. Chem. Soc., Dalton Trans. 3591 (1990) and references therein.

20. (a) K.-T. Wong and T.-Y. Luh, J. Am. Chem. Soc. 114, 7308 (1992). (b) K.-T. Wong, T.-M. Yuan, M.C. Wang, H.-H. Tung and T.-Y. Luh, J. Am. Chem. Soc. 116, 8920 (1994).

21. (a) W.-L. Cheng, S.-M. Yeh and T.-Y. Luh, J. Org. Chem. 58, 5576 (1993). (b) For a recent review on the regioselective cleavage reactions of acetals with Grignard reagents, see: T.-Y. Luh, Pure Appl. Chem. in press.

22. For a review, see: J.-F. Normant, I. Marek andJ.-M. Lefrançois, Pure Appl. Chem. 64, 1857 (1992).

23. H.-R. Tseng, unpublished results.

24. W.-L. Cheng and T.-Y. Luh, J. Org. Chem. 57, 3516 (1992).

25. (a) Y.-L. Tzeng, T.-Y. Luh and J.-M. Fang, J. Chem. Soc., Chem. Commun. 399 (1990). (b) Y.-L. Tzeng, W.-L. Cheng and T.-Y. Luh, Z. Naturforsch. 50B, 385 (1995).

26. W.-L. Cheng and T.-Y. Luh, J. Chem. Soc., Chem. Commun. 1392 (1992).

27. P.-F. Yang, Z.-J. Ni and T.-Y. Luh, J. Org. Chem. 54, 2261 (1989). (b) Y.-L. Tzeng, P.-F. Yang, N.-W. Mei, T.-M. Yuan, C.C. Yu and T.-Y. Luh, J. Org. Chem. 56, 5289 (1991). (c) T.-M. Yuan and T.-Y. Luh, J. Org. Chem. 57, 4550 (1992). (d) T.-M. Yuan and T.-Y. Luh, Org. Syn. in press. 